\title{
Unique Ways in Which the Quality of Friendships Matter for Life Satisfaction
}

\author{
Victor Kaufman ${ }^{1}$ (D) Anthony Rodriguez ${ }^{1,3} \cdot$ Lisa C. Walsh $^{1} \cdot$ Edward Shafranske $^{2}$. \\ Shelly P. Harrell ${ }^{2}$
}

Accepted: 24 January 2022 / Published online: 5 March 2022

(C) The Author(s) 2022

\begin{abstract}
The quality of individuals' social relationships consistently predicts greater well-being. But little is known about the relative importance of different relationship types for life satisfaction, including the relative importance of friendships compared to other types of relationships. Some have theorized that one intimate relationship is all you need. However, romantic partners, family, and friends may contribute uniquely or interactively to well-being. The current study assessed life satisfaction and relationship satisfaction in survey data collected from a large, diverse sample of respondents. Satisfaction with each type of relationship was significantly and independently associated with life satisfaction, over and above other variables in the model. Friendship (not family) interacted with intimate relationships: when respondents were highly satisfied with their intimate relationships, they were happy with their lives regardless of friendship quality. But when they were unhappy with their intimate relationships, they were only happy with their lives if they had good friends.
\end{abstract}

Keywords Friendship $\cdot$ Relationships $\cdot$ Well-being $\cdot$ Life satisfaction

People who are socially integrated and satisfied with their relationships are happier, healthier, and live longer (Baumeister, 1995; Beller \& Wagner, 2018). However, not all social relationships are equivalent. Intimate partners are involved in our romantic, economic, and parenting lives, and the intensity of these relationships is often greater than other types of relationships (Argyle, 2001; Bodenmann et al., 2014). Family members play unique roles in that we are legally and biologically bound to them, and we have life-long relationships with many of them (Fuller-Iglesias et al., 2015). Friendships, in contrast, are voluntary relationships that can be sources of emotional support and companionship (Demir, 2015). For a satisfying life, one strong intimate relationship might be sufficient (Coyne \& DeLongis, 1986), especially if the needs fulfilled by intimate relationships are more important

Victor Kaufman

victor.kaufman@iac.com

1 Department of Psychology, University of California, Los Angeles, 1285 Franz Hall, Box 951563,

Los Angeles, CA 90095-1563, USA

2 Pepperdine University, Malibu, CA, USA

3 RAND Corporation, Boston, MA, USA 
than the needs other relationships fulfill. Yet, because all three types of relationships are rarely examined at the same time, the way different kinds of relationships may contribute uniquely or interactively to well-being remains unknown (Birditt \& Antonucci, 2007; Cheng et al., 2011). The current study aimed to fill this gap by drawing on cross-sectional survey data that assessed well-being and satisfaction with different types of social relationships in a large and diverse sample.

\section{Different Relationships, Different Functions}

Social networks of individuals contain different kinds of relationships (e.g., with romantic partners, friends, and family). Yet researchers interested in social relationships and well-being often treat all of these relationships as an undifferentiated group, or assess each relationship type separately (e.g. Fuller-Iglesias et al., 2015).

Among married people, the quality of the spousal relationship is significantly associated with many outcomes, including well-being (Proulx et al., 2007). Partners spend considerable time together, share experiences, socialize and raise children together, and, due to their proximity, have the ability to shape their partner's future development (Hoppmann et al., 2011). However, not all intimate relationships are equal (Dush \& Amato, 2016; Lehmann et al., 2014). Happy marriages bring psychological benefits, but unhappy ones bring serious costs (Dush et al., 2008; Hawkins \& Booth, 2005). Furthermore, some partners concentrate on other aspects of their lives, such as work, outside activities, or relationships with family and friends (Huston et al., 2001). This raises the possibility that a person can be in an unhappy marriage but still have a relatively happy life.

Family (primarily parents, children, and siblings) play a complex role in well-being and happiness. These ties often represent the closest relationships within our social networks, are perceived as a resource for support and dealing with stress and are positively associated with psychological well-being (Birditt \& Antonucci, 2007; Fuller-Iglesias et al., 2015). However, conflict within family relationships, especially sustained conflict, enhances depressive symptoms and decreases life satisfaction (Antonucci et al., 2011). More family conflict is associated with lower well-being (North et al., 2008). With all of these cross-pressures, family relationships are often regarded more ambivalently than non-family relationships (Fingerman et al., 2004; Fuller-Iglesias et al., 2013).

Although researchers study friends less frequently (Gillespie et al., 2014), friendships should also be associated with well-being because friends can serve functions that lovers and family rarely do (Walen \& Lachman, 2000). Friendships tend to be voluntary positive relationships (Wright, 1969). Perhaps as a consequence, they are a major source of positive affect, and act as a buffer against issues with spouses (Argyle, 2001; Burger \& Milardo, 1995; Demir, 2015). Accordingly, greater support from friends is associated with higher personal well-being (Antonucci et al., 2001; Walen \& Lachman, 2000), especially for married people (Cheung et al., 2015). A study of social connectivity in the internet era found that, in contemporary Western societies, friendships still function as the primary socialization relationship (Hua Wang \& Wellman, 2010). 


\section{The Relative Importance of Different Relationships for Well-Being}

While the three primary types of relationships are unique, we cannot know the relative importance of these different relationships for well-being, or how different types of relationships in combination are associated with well-being, until all of these relationships are assessed in the same study. There are several different ways that the quality of the three primary relationship types might combine to account for well-being.

\subsection{Is Romantic Love All You Need?}

Some have argued that romantic "love is all you need" and that nothing other than a solid intimate relationship contributes to well-being due to threshold or ceiling effects (Coyne \& DeLongis, 1986). The belief that romantic relationships in adulthood replace the mother as a person's primary attachment figure reinforces this view (Ainsworth, 1989; Zeifman \& Hazan, 2018). Romantic partners "typically feel safer and more secure when their partner is nearby, accessible, and responsive" (Fraley \& Shaver, 2000 p. 2). However, love often exists outside of romantic relationships, as evidenced by phrases like "brotherly love" and the Greek word "agape," which refers to one's love for friends and family (Mohacsy, 1992). Over the years, an expanded view of attachment developed to include all of a person's closest relationships (Takahashi, 2005), a group which typically includes parents, siblings, and at times, a best friend who is a "uniquely valued person, not interchangeable with others" (Ainsworth, 1989, p. 714). Researchers interested in this area have adopted the expanded attachment group theory when defining relationship types that may be uniquely and positively associated with well-being, suggesting that more than romantic love is necessary to achieve optimum levels of happiness (Birditt \& Antonucci, 2007; Ratelle et al., 2012).

\subsection{Does Each Relationship Type Contribute Separately to Well-Being?}

To the extent that each of the primary relationship types satisfies unique needs, it may follow that the quality of those relationships, when studied simultaneously, will be associated with well-being independently. In a study evaluating this idea (Ratelle et al., 2012), researchers investigated students' perceived support for their autonomy from partners, parents, and friends and its association with subjective well-being. The researchers found that more autonomy support from each important relationship contributed to higher well-being scores, with the highest levels of subjective well-being achieved when all sources were the most positive. This study suggests that strong relationships with our intimate partners, family, and friends all contribute to happiness and well-being. A limitation of the study, however, is that it only included university students. It is not clear whether the same results would generalize within representative samples of adults. Further, this study only examined the quality of autonomy support within each relationship. There has yet to be a study examining the quality of these relationships more broadly.

\subsection{Can a Few Good Relationships Promote Happiness?}

It might also be the case that well-being requires some good relationships, but it might not matter which ones because the good compensate for the bad. Birditt and Antonucci 
(2007) tested this premise. Respondents were asked to rate the quality of their relationships with their spouse, mother, father, children, and same-sex best friend. They discovered that married individuals with a best friend need high quality relationships within only two of the main relationships (spouses, family members, and friends) to be happy, and that a good relationship with the spouse was not essential. If respondents did not have a best friend, however, then the spousal relationship became more important for well-being. This is the first study in which authors find that a strong, high quality relationship with a spouse may not be a necessary component for positive well-being. A moderate relationship with a spouse, plus a good relationship with either family or friends, may support well-being as well.

\subsection{Do Different Types of Relationships Interact?}

Finally, it could be that particular configurations of relationships matter more or less for well-being. To our knowledge, no existing research directly examines how the quality of relationships with intimate partners, family members, and friends may interact with each other to account for well-being. These interactions can exist in four ways: three two-way interactions (i.e. intimate partners interacting with friends; intimate partners interacting with family; and friends interacting with family) and one three-way interaction (i.e. intimate partners, family, and friends interacting with each other). We are interested in knowing whether the association between any of our predictors (intimate relationships, family relationships, and friends) and life satisfaction differs significantly at various levels of another predictor variable.

\subsection{Application of Theory}

Consistent with prominent theories about social relationships, romantic relationships and close friendships may be more critical to well-being than family relationships. First, attachment theory recognizes that best friends (in addition to romantic partners) may serve as attachment figures for adults (Antonucci et al., 2004; Birditt \& Antonucci, 2007; Burger \& Milardo, 1995; Ratelle et al., 2012). The Social-Brain Hypothesis, developed by the anthropologist R.I.M. Dunbar, reinforces this belief. It typically includes "best friends" among people's layer of closest relationships (Sutcliffe et al., 2012). A third theory-the self-expansion theory (i.e. the inclusion-of other-in-the-self principle), created by Aron and colleagues $(2005$; 2004), also is applicable to best friends (in addition to romantic partners), especially in the context of shared activities "encourag[ing] exploration and noveltyseeking behavior" (Mattingly et al., 2012, p. 124).

Finally, there is the Belongingness Hypothesis (Baumeister, 1995) that proposes people need frequent contact with others, and second, that these interactions should be positive and pleasant, or at the very least mostly free from conflict or negativity. Researchers in this area have primarily applied the hypothesis to romantic relationships and friendships (i.e., best and close friends), reporting significant associations between positive affect in such relationships and well-being (Lyubomirsky et al., 2005).

When it comes to well-being, the above theories (especially the Belongingness Hypothesis) suggest that close friendships (not family) will interact with romantic relationships, because friendships tend to be positive, while family relationships often involve greater negativity (Fuller-Iglesias et al., 2013, 2015). In other words, the association between 
romantic partner satisfaction and life satisfaction may differ depending on friendship (not family) satisfaction.

\section{Are There Configurations of Relationships Associated with More or Less Well-Being?}

However, across all of their relationships, different people may configure their social networks in different ways. Some may have networks that emphasize family involvement, while others might have networks that emphasize friendships. Researchers can test the potential differences of such networks on well-being using cluster analysis, a statistical approach that involves the creation of uniquely classified groups. The goal of this approach is to create groups of cases (i.e., clusters) that are relatively homogeneous within themselves and heterogeneous between groups (Yim \& Ramdeen, 2015). Cluster creation results in the establishment of distinct heterogeneous groups in which the observations within each group have low levels of variances from the centroid of each cluster (Henry et al., 2005; Mirkin, 2013). Once groups are identified, researchers can compare separate clusters against a specified dimension, such as well-being.

A prominent example of cluster methodology is work done by Birditt and Antonucci (2007). This study found five clusters, ranging from high positivity and low negativity rating for all relationships to the opposite rating for all relationships. There are several other cluster analyses of social networks (Fiori et al., 2006, 2007; Litwin \& Stoeckel, 2013). These studies found four primary clusters of network types: (1) diverse, (2) family-focused, (3) friend-focused, and (4) restricted. The diverse network, with values above the mean for almost all criterion variables, was the largest and was associated with highest subjective well-being (as evidenced by lower depressive symptomatology). Restricted networks had the most limited network ties with all criterion variables below the mean and was the grouping with the lowest well-being. With respect to family-focused and friendshipfocused clusters, the findings were mixed.

\section{Overview of the Current Study}

Existing research suggests that intimate relationships, family relationships, and friendships are each important to people's well-being (Lyubomirsky et al., 2005). In light of limited and inconsistent findings that distinguish among possible configurations of people's three primary relationship types and their associations with well-being, we intend to build on existing research to examine how each of these three types of relationships account for life satisfaction, a cognitive, evaluative aspect of well-being. To this aim, we implemented a cross-sectional survey that recruited a large, diverse sample and assessed participants' life satisfaction and relationship satisfaction with romantic partners, family members, and friends. We used multiple regression analyses, with interactions, and a cluster analysis to determine whether specific configurations exist.

Based on existing research, we hypothesized the following:

- Hypothesis 1: Satisfaction with intimate partners, family members, and friends will each be significantly associated with life satisfaction, over-and-above the main effects 
of each other. This finding will replicate and expand (with a broader sample and more generalized measures of satisfaction) on the findings in Ratelle et al. (2012).

- Hypothesis 2: Friendships (not family) will interact with intimate relationships, such that the association between satisfaction with intimate relationships and life satisfaction will differ depending on levels of satisfaction with friends. We believe that family relationships, due to potentially high levels of conflict, will not so interact.

- Hypothesis 3: A cluster analysis will show multiple, distinct configurations of respondents' satisfaction with intimate relationships, satisfaction with family, and satisfaction with friends (e.g., clusters that represent high levels of satisfaction with each relationship type and clusters in which friendship satisfaction is high, but marital satisfaction is low). When the respondents within each cluster are measured by their levels of life satisfaction, the clusters will be significantly different from each other on life satisfaction, with friendship satisfaction, whether providing high or low life satisfaction, providing a significant differentiating factor within each cluster.

\section{Method}

\subsection{Sampling}

In 2014, a private research firm, Research Now, solicited participants from an existing panel of over 600,000 individuals in the United States who had voluntarily consented to be invited to participate in survey research online. The sampling frame was designed to reflect the diversity of the U.S. Census, such that more effort was devoted to soliciting data from harder-to-reach demographic groups.

\section{Participants}

A total of 2,013 adults completed the survey. They ranged from 18 to 75 years of age and represented a broad sample of the U.S. population on demographic characteristics such as ethnicity, income, and education. Because the current analysis addressed questions relevant to individuals who were in long-term relationships, the analyses described below examined data from the 972 participants who indicated either that they were married or that they were living with a lifetime partner.

Of these 972 respondents, $485(50 \%)$ were men and 487 (50\%) were women. Men's mean age was 49.5 years $(S D=13.9)$, while women's mean age was $48.7(S D=14.1)$. Of the men, $14.2 \%$ were between the ages of $18-34 ; 27.4 \%$ were between the ages of $35-44$; $20.2 \%$ were between the ages of $45-54$; and $38.2 \%$ were age 55 or older. Of the women, $21.7 \%$ were between the ages of $18-34 ; 16.1 \%$ were between the ages of $35-44 ; 25.1 \%$ were between the ages of $45-54$; and $37.1 \%$ were age 55 or older. The sample was $67.9 \%$ White, 9.5\% Black, 12\% Hispanic/Latino, 4.1\% Asian American, 1.4\% Native American, and $5.1 \%$ other. With respect to income, $9.7 \%$ of the respondents earned less than $\$ 25,000$ per year; $19.4 \%$ earned between $\$ 25,000$ and $\$ 49,999$ per year; $38.3 \%$ earned between 50,000 and $\$ 99,999$ per year; $25.9 \%$ earned between $\$ 100,000$ - $\$ 199,999$ per year; and $6.7 \%$ earned over $\$ 200,000$ per year. With respect to education, $0.1 \%$ of the respondents had less than a high school degree; $10.5 \%$ had a high school or equivalent degree; $21.0 \%$ 
had some college; $11.5 \%$ had a vocational degree or certificate; $30.8 \%$ were college graduates; and $26.1 \%$ had post-college degrees.

\section{Procedure}

Respondents who agreed to participate were invited via e-mail to complete a self-report online survey that included questions about demographics, personal relationships (e.g., with friends, spouses, and family), and other aspects of their lives (e.g., health, career, and involvement within the community). Completing the survey took approximately $30 \mathrm{~min}-$ utes on average. Respondents received compensation (e.g., cash, points, or sweepstakes entry) for participating.

\section{Measures}

\subsection{Life Satisfaction}

The survey included two separate measures assessing constructs related to life satisfaction and well-being: the Personal Wellbeing Index (PWI) (International-Wellbeing-Group, 2013) and the Satisfaction with Life Scale (SWLS) (Diener et al., 1985). The PWI assesses subjective well-being across multiple domains: standard of living, health, life achievement, personal relationships, safety, community cohesion, future security, and spirituality. Within each of these eight domains, participants indicated their level of satisfaction on an 11-point response scale with $0=$ completely dissatisfied and $10=$ completely satisfied. Within the current data, Cronbach's alpha was 0.89. The SWLS is a 5-item instrument measuring global satisfaction with life (e.g., "I am satisfied with my life."), rather than the specific domains assessed by the PWI. The response choices range from $1=$ strongly disagree to $7=$ strongly agree. The SWLS has been shown to have good discriminant and convergent validity, test-retest reliability, and internal consistency reliability (Pavot \& Diener, 2008) and has been shown to be insensitive to current mood (Eid \& Diener, 2004). In the current data, Cronbach's alpha for the SWLS was 0.90 .

Some have argued that respondents, when answering the global items on the SWLS, take into account the specific domains of the PWI (Corrigan et al., 2013). Indeed, in the current data total scores on the PWI and the SWLS correlated strongly $(r=0.69, p<0.001)$. Given that the two measures, while conceptually distinct, may in practice assess the same underlying construct, we explored combining the items on the two measures. Cronbach's alpha for all 13 items was 0.92 . In light of the overlap between the scales, the analyses that follow treat the sum of the responses on the two instruments divided by the total number of items as an index of life satisfaction, with a potential range from 0.38 to 9.46 .

\subsection{Satisfaction with Romantic Partner}

One item in the survey addressed satisfaction with romantic partner and asked: "Please rate ... the degree of happiness/satisfaction you derive from your relationship with your romantic partner." The response choices were: $1=$ high unhappiness, $2=$ mostly unhappiness, $3=$ mostly happy, and $4=$ high happiness . 


\subsection{Satisfaction with Family}

Three items in the survey assessed satisfaction with relationships to parents, children, and extended family members. Response choices were the same as those used to evaluate romantic partners. To address cases where respondents did not have children, extended family, or living parents, the average of any completed items was used as the score for each respondent. Cronbach's alpha for the 3-item scale was 0.61 .

\subsection{Satisfaction with Friendships}

Based on existing literature on the dimensions of friendship (e.g., degrees of closeness/ intimacy, common shared enjoyable experiences) we selected seven items to represent satisfaction with friendships (Demir et al., 2015; Kaufman, 2020; Lewis, 2015; Reis, 2001). Example items include: "I have friends to whom I can confide my deepest concerns," "I have friends with whom I share values," and "I have friends with whom I have fun." For each statement, respondents chose from three possible responses: $1=$ does not describe me, $2=$ describes me somewhat, and $3=$ very much describes me. Cronbach's alpha for the 7 -item scale was 0.80 .

\section{Analysis Strategy}

To assess the independent and interactive associations between life satisfaction and satisfaction with romantic partners, family members, and friends, we ran forward multiple regression models. Age and income (the only two demographic variables we measured that were significantly associated with life satisfaction) were entered into all models as control variables.

To identify cases with social networks that were relatively homogeneous within themselves and heterogeneous between groups, we conducted a cluster analysis (Yim \& Ramdeen, 2015) using a hierarchical algorithm to define the number of clusters, followed by non-hierarchal clustering (i.e., K-means clustering). While the use of a hierarchal algorithm is adequate in certain situations, the K-means methodology is better suited for large data samples. The K-means approach initially identifies a set of means (i.e., centroids) and classifies cases based on their distance from such centroids, with each case assigned to its closest center. When completed, the K-means method partitions all cases into non-overlapping clusters, minimizing within-cluster variances from the centroids (Mirkin, 2013). This is a common approach that results in discrete clusters (Henry et al., 2005; Ketchen \& Shook, 1996).

With this methodology, we (1) identified the variables from which we wanted to create distinct profiles; (2) determined whether to standardize the variables; (3) defined, a priori, the number of variables through a hierarchal algorithm; (4) applied the K-mean algorithm to create mutually exclusive groups of respondents; and (5) validated our selection of the number of clusters.

We chose to base the cluster analysis on our three primary independent variables: levels of satisfaction with intimate relationships, family relationships, and friendships. Since our variables had unequal measuring scales, we standardized each variable using Z-scores $(M=0 ; S D=1)$. Next, we used the hierarchal clustering tool in SPSS to define the number 
of clusters. In this regard, to measure distances between cases, we utilized squared Euclidian distance (best suited for continuous variables); in terms of linkage, we used Ward's method that creates clusters of cases based on degrees of similarity and minimizes the within-cluster sum of squares (Henry et al., 2005; Ketchen \& Shook, 1996; Yim \& Ramdeen, 2015). Further, once we ran the algorithm, we observed the incremental changes in the agglomeration coefficients at each stage and visually inspected the Dendrogram (a graph of the order of combination of clusters in each stage in the output) and determined that three cluster solution provided the best fit to our data (Ketchen \& Shook, 1996; Yim $\&$ Ramdeen, 2015). Finally, we validated our selection of the number of clusters in a variety of ways based on interpretability, the desire for a parsimonious number of clusters, comparison of a different number of clusters, disregard of highly fragmented clusters, and through the use of the elbow method, assessing total within-cluster sum of squares (Birditt \& Antonucci, 2007; Kassambara, 2017; Milligan \& Cooper, 1985; Mirkin, 2013).

\section{Results}

\subsection{Preliminary Analyses}

On average, respondents reported relatively high satisfaction with their romantic relationships $(M=3.4, \max =4, S D=0.67)$, their family relationships $(M=3.2, \max =4$, $S D=0.52)$, their friendships $(M=2.4, \max =3, S D=0.44)$, and their life overall $(M=6.3$, $\max =8.85, S D=1.4)$. Satisfaction ratings of the three different types of relationships were significantly positively correlated ( $\underline{r s}$ ranged between 0.15 and 0.34 , all $p s<0.001$ ), but not so high that the three scores could not be examined independently for their associations with life satisfaction.

\section{Multiple Regression Models}

To estimate the independent associations between satisfaction with each type of relationship and satisfaction with life overall, we performed multiple regression analyses in which life satisfaction was predicted by satisfaction with the intimate relationship, satisfaction

Table 1 Hierarchical regression models (full sample) with life satisfaction as the dependent variable

\begin{tabular}{lllll}
\hline & $b(\mathrm{SE})$ & $t$ & $b(\mathrm{SE})$ & $t$ \\
\hline Age & $0.19(0.04)$ & $4.76^{* * * *}$ & $0.19(0.04)$ & $4.81^{* * *}$ \\
Income & $0.22(0.04)$ & $5.53 * * *$ & $0.22(0.04)$ & $5.46^{* * * *}$ \\
Intimate relationship satisfaction & $0.41(0.04)$ & $9.92^{* * *}$ & $0.86(0.20)$ & $4.34 * * *$ \\
$\quad$ MS) & & & & $3.83 * * *$ \\
Friend satisfaction (QL) & $0.29(0.04)$ & $7.36^{* * *}$ & $0.72(0.19)$ & $5.74 * * *$ \\
Family satisfaction & $0.25(0.04)$ & $6.01 * * *$ & $0.24(0.04)$ & $-2.32^{* * *}$ \\
MS*QL & - & - & $-0.67(0.29)$ & \\
\hline
\end{tabular}

All $b$ coefficients standardized and centered; $R^{2}$ change between two models significant $(F$ change $=0.02)$; $N=925$ for base model; $N=921$ for model with interaction

$* p<0.05 ; * * p<0.01 ; * * * p<0.001$ 
with friends, and satisfaction with family, controlling for age and income. As Table 1 reveals, satisfaction with each type of relationship was significantly $(p<0.001)$ and independently associated with life satisfaction, over and above the other variables in the model.

Building on the base model, we then added the three two-way interactions and one three-way interaction. Forward regression procedures were employed. The final model was significant, $F(6,921)=65.826, p<0.01, R^{2}=0.30$, retaining, in addition to age and income, satisfaction with the intimate relationship, satisfaction with family, satisfaction with friends, and the interaction between satisfaction with the intimate relationships and satisfaction with friends. All predictors were positively associated with life satisfaction, except the interaction which was negatively associated with life satisfaction $(p<0.05)$.

To illustrate the interaction, Fig. 1 illustrates the associations between satisfaction with the intimate relationship and life satisfaction at different levels of satisfaction with friends, specifically at -1 standard deviation below the mean, at the mean, and at +1 standard deviation above the mean. Two of our slopes are significantly different from zero $(b=0.47$, $p<0.01 ; b=0.19, p<0.001 ; b=0.10, p<0.07)$ and outside the region of significance from 0.99 to an upper bound equal to 4.50 . When respondents were highly satisfied with their intimate relationships, they were happy with their lives regardless of the quality of their friendships. But when they were unhappy with their intimate relationships, they were only happy with their lives if they had satisfying friendships.

\section{Cluster Analysis}

The K-means method produces clusters with the greatest amount of distance between clusters. With the use of hierarchal and K-mean clustering algorithms, we defined three distinct configurations (see Table 2) of respondents' intimate relationship satisfaction, family satisfaction, and friendship satisfaction. The clusters (with each variable

Fig. 1 Association between satisfaction with intimate relationships and life satisfaction at different levels of satisfaction with friends. $\mathrm{Y}=$ life satisfaction (4-7). X=intimate relationship satisfaction $(-1$ to 1$) . Z=$ quality of friends (green, red, and black lines). Green line = high quality of friends. Red line $=$ moderate quality of friends. Black line $=$ low quality of friends

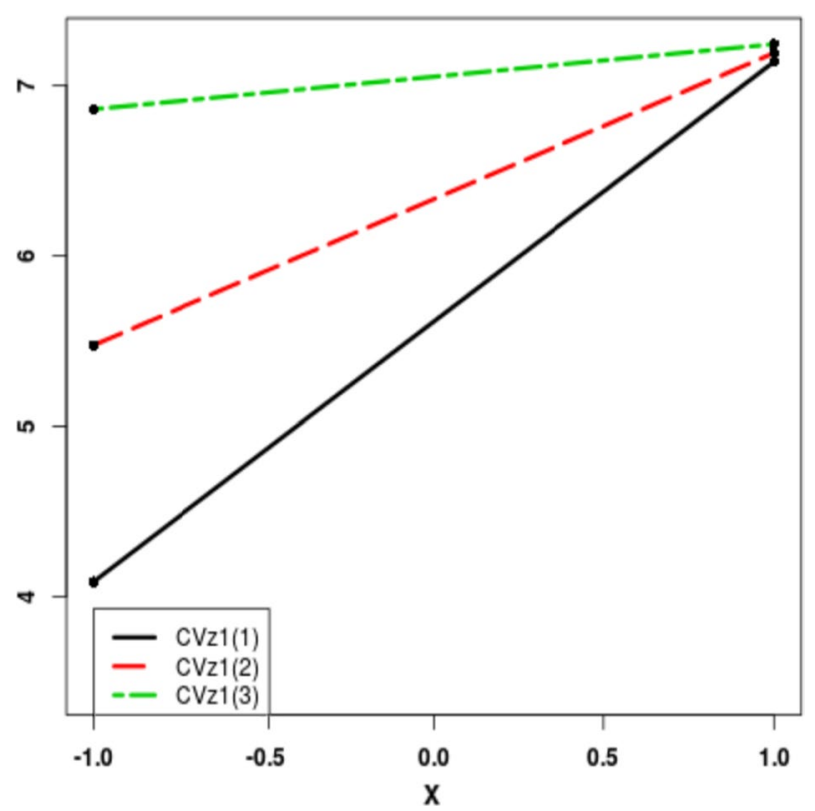


Table 2 K-mean descriptives of cluster analysis

\begin{tabular}{|c|c|c|c|}
\hline Variable (Range) & $\begin{array}{l}\text { Cluster } 1 \\
\text { M (SD) } \\
\text { (Range) }\end{array}$ & $\begin{array}{l}\text { Cluster } 2 \\
\text { M (SD) } \\
\text { (Range) }\end{array}$ & $\begin{array}{l}\text { Cluster3 } \\
\text { M (SD) } \\
\text { (Range) }\end{array}$ \\
\hline $\begin{array}{l}\text { Life satisfaction } \\
(1.23-8.85)\end{array}$ & $\begin{array}{l}6.89(1.14) \mathrm{a} \\
N=421 \\
(2.46-8.85)\end{array}$ & $\begin{array}{l}6.05(1.42) \mathrm{b} \\
N=312 \\
(1.23-8.8)\end{array}$ & $\begin{array}{l}5.70(1.40) \mathrm{c} \\
N=239 \\
(1.54-8.85)\end{array}$ \\
\hline
\end{tabular}

Each cluster measured by life satisfaction significantly differed from each other at the $p<.001$ level

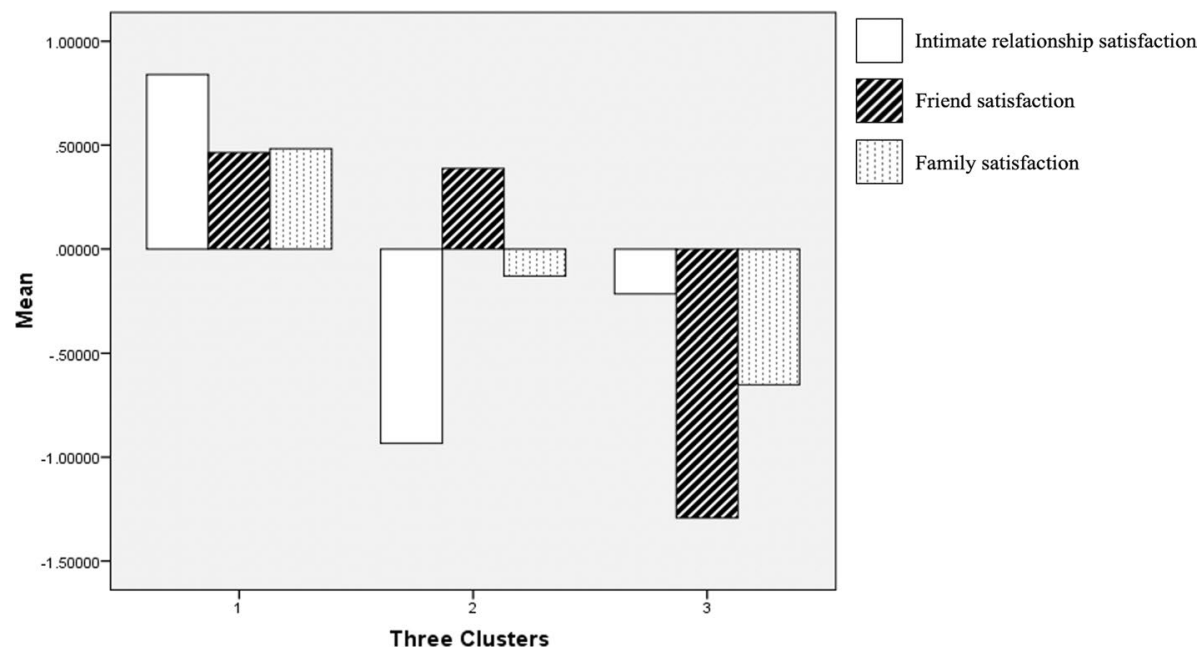

Fig. 2 Three distinct configurations of intimate relationship satisfaction, friend satisfaction, and family satisfaction

standardized with $M=0$ and $S D=1$ ), are described in Fig. 2. As the figures reveal, in Cluster $1(n=421)$, respondents reported high levels of satisfaction with intimate relationships, family, and friends (approximately one standard deviation above the mean intimate relationships, and approximately one-half a standard deviation above the mean for family relationships and friendships). In Cluster $2(n=312)$, respondents reported high satisfaction with friends (one-half a standard deviation above the mean), but low satisfaction with romantic partners and family (one standard deviation below the mean for intimate relationships). In Cluster $3(n=239)$, respondents reported low levels of satisfaction with all three relationships (more than one SD below the mean for quality of friends).

When we compared the average levels of life satisfaction within each cluster, each was significantly different $(p<0.001)$ from the others (see Table 2), with Cluster 1 reporting the highest life satisfaction, Cluster 3 the lowest, and Cluster 2 falling in the middle.

We compared the demographic characteristics (i.e., gender, age, income, ethnicity, parenthood, levels of education, and employment status) of respondents categorized within each of the three configurations of relationships. The members of each cluster differed on age and income (Table 3) but did not differ significantly on any other demographic 
Table 3 Cluster descriptives

\begin{tabular}{llll}
\hline & Cluster 1 & Cluster 2 & Cluster 3 \\
\hline Mean age & $\mathrm{M}=48.29 ;$ & $\mathrm{M}=50.55 ;$ & $\mathrm{M}=48.77 ;$ \\
& $\mathrm{SD}=15.12^{*}$ & $\mathrm{SD}=12.98^{*}$ & $\mathrm{SD}=13.19$ \\
$\begin{array}{l}\text { Mean income } \\
\text { (based on income } \\
\text { categories) }\end{array}$ & $\mathrm{M}=3.07 ;$ & $\mathrm{M}=3.13 ;$ & $\mathrm{M}=2.82 ;$ \\
\hline
\end{tabular}

*Clusters 1 and 2 significantly different based on age. $\mathrm{X}=$ Clusters 1 and 3 significantly different based on age categories. $Y=$ clusters 2 and 3 significantly different based on age categories

variable. The mean age was significantly higher for Cluster 2 as compared to Cluster 1. Participants' mean income was significantly greater in Clusters 1 and 2 than in Cluster 3.

\section{Discussion}

Social relationships matter, especially our relationships with our intimate partners, family members, and friends (Argyle, 2001; Caunt et al., 2013; Myers, 1999). However, only a few studies have examined the independent associations between the quality of each of these relationships and overall well-being (Chopik, 2017; Thomas, 2016). We sought to elaborate on these associations in a number of ways.

\section{Simultaneous Assessment of Relationship Types}

First, we wanted to know whether the three primary relationship types-romantic, family, and friend relationships-were each significantly associated with life satisfaction, over and above the main effects of each other. We found that, controlling for age and income, each did account for significant, unique variance in well-being over each other, confirming Hypothesis 1 . This refutes the argument that romantic love is the only thing that matters for well-being and replicates the finding in Ratelle et al. (2012). Our finding also builds on Ratelle by broadening the sample (in terms of age and gender, among other factors) and using more refined measures of life satisfaction (i.e., both overall life satisfaction and domain satisfaction) and relationship satisfaction (i.e., with romantic partners, friends, and family).

\section{Two Types of Analysis}

If an intimate relationship is not sufficient to be happy, then what other relationships do people need to be satisfied with their lives? Are quality relationships with two relationship types adequate to achieve happiness? If so, does it matter which ones? Or, does a person need high-quality relationships with all three relationship types to be happy? We assessed these questions using both a variable-centric and a person-centric approach, following techniques utilized in Ratelle et al. (2012). Our variable-centric approach used regression 
models that included interactions, while our person-centric approach used a cluster analysis that identified groups of individuals who shared identified characteristics.

With our variable-centric approach, we tested the interactions between our three variables. Only the interaction between intimate relationship satisfaction and quality of friendships was significant. When intimate relationship satisfaction is high, level of friendship satisfaction does not predict life satisfaction. If intimate relationship satisfaction is low, however, people were only happy with their lives if they had good quality friends. This suggests that people can be happy in their lives even if they are not completely satisfied with their intimate relationships, as long as they have good friends, confirming Hypothesis 2 .

Do such people exist? To address that question, we used a person-centric approach through a cluster analysis, identifying three groups of people with significantly different configurations (high, moderate, or low) of satisfaction with their intimate relationships, family, and friend relationships. We measured each groups' level of life satisfaction and confirmed Hypothesis 3: average levels of satisfaction were significantly different within each cluster. Our findings were consistent with the negative interaction between intimate relationship satisfaction and friendship satisfaction. One group (representing $43 \%$ of our sample) reported high mean levels of satisfaction with each relationship type and high levels of life satisfaction. Another group (representing 25\% of our participants) reported moderate levels of satisfaction for intimate relationships and low levels of satisfaction for family and friends, with friends at a particularly low level (i.e. more than 1 standard deviation below the mean). The third group, i.e. Cluster 2 (representing $32 \%$ of our participants), was the most interesting. This group was comprised of people who had high quality satisfaction with friends significantly above the mean, moderate satisfaction with family at the mean, and low satisfaction with intimate relationships significantly below the mean. For this group, life satisfaction was significantly below the life satisfaction of our first group, but significantly higher than the life satisfaction of our second group. This illustrates that a person can still be relatively happy in life, even if their intimate relationship satisfaction is poor. It is relevant that friendship satisfaction is the lowest in the group that has the lowest mean level of life satisfaction.

Since our cluster analysis is only exploratory, the question exists whether there might be other possible clusters. We think that they might exist; however, in all likelihood, they would be variations on the three themes of the clusters we have discovered. For example, we think that (while it is the case that friendship satisfaction does not add to a person's happiness if they are extremely happy in their romantic relationship), this may not be true when relationship satisfaction is just moderately strong. In such cases, strong friendship satisfaction may contribute in a meaningful way to marriage stability and thereby enhance well-being, over-an-above the satisfaction from the marriage. On the other hand, as is suggested in (Birditt \& Antonucci, 2007), there may be a cluster of people who have relatively weak relationship satisfaction, but strong friendship and family satisfaction that acts as an offset to such marital satisfaction, such that well-being might be at least moderately strong. These other clusters if they exist, would provide greater evidence that the quality of friendships may be key when assessing life satisfaction of intimate relationship partners. Further, the attributes of friendships may be especially important for such relationship partners. For example, VanderDrift et al. (2012) equated enhanced friendship between a dyad to love, broadly defined. Specifically, they found that the more people were willing to invest in their friendship with their romantic partners, the greater the rewards they reaped in their romantic relationships. More research is needed to test these premises, as well as to consider other possible clusters of relationship satisfaction. 


\section{Strengths and Limitations}

Confidence in our findings is heightened by several strengths of our research methods and design. First, we used a sample that mirrored the U.S. population, which enabled us to ascertain whether our results generalize across individuals who vary demographically. Second, our sample was large-almost 1,000 participants, which enhanced our power to identify differences between groups. Third, we used broad and reliable measures of life satisfaction. Finally, our pattern of findings was robust across both personcentric and variable-centric models.

On the other hand, generalizations from these results are constrained by several limitations of this research. First, our study assessed data obtained through a self-report survey; these surveys contain measures that are often susceptible to positive reporting bias. Second, we based our intimate relationship satisfaction variable on a single item, which is not as reliable as a multi-item scale. Third, we did not collect information on participants' marital/romantic relationship duration, which could impact results. Future studies should examine how relationship duration moderates the association between relationship satisfaction and life satisfaction (e.g., Anderson et al., 2010). Fourth, since we administered our survey at one point in time, our findings are cross-sectional; therefore, we are unable to draw any causal conclusions. Happier people tend to have better social relationships (Diener \& Seligman, 2002), so the possibility of an inverse causal relationship (high life satisfaction leading to greater relationship satisfaction) cannot be excluded. Further, relationship satisfaction and life satisfaction could form a bi-directional relationship that initiates upward spirals of enhanced well-being (Fredrickson \& Joiner, 2002), whereby stronger relationships lead to higher life satisfaction, which in turn leads to even stronger relationships, and so forth. Finally, replication studies are needed to determine the reliability of effects described here.

\section{Conclusion}

To our knowledge, our study is the first to examine how three primary social relationship types (romantic partners, family, and friends) independently and interactively contribute to life satisfaction. As such, it has important empirical and theoretical implications that expand basic knowledge on the importance of social connections to human well-being. The most important finding indicates that strong friendships may be vital for people with romantic partners, especially if they are dissatisfied with their intimate relationships. People who are unhappy with their partners can still find happiness if they have good friends. Clinicians should be aware of this finding and be prepared to probe the strengths and weaknesses of friendships when assessing their client's romantic and life satisfaction. Researchers should also continue to study friendships more closely (an understudied construct), as it may be "the single most important factor influencing ... our happiness" (Dunbar, 2018 p. 32).

Funding Institute for the study of adult friendships. 


\section{Declarations}

Conflict of interest We have no known conflicts of interest to disclose. Our work was funded by the Institute for the Study of Adult Friendships, a non-profit organization financed by Victor Kaufman.

Open Access This article is licensed under a Creative Commons Attribution 4.0 International License, which permits use, sharing, adaptation, distribution and reproduction in any medium or format, as long as you give appropriate credit to the original author(s) and the source, provide a link to the Creative Commons licence, and indicate if changes were made. The images or other third party material in this article are included in the article's Creative Commons licence, unless indicated otherwise in a credit line to the material. If material is not included in the article's Creative Commons licence and your intended use is not permitted by statutory regulation or exceeds the permitted use, you will need to obtain permission directly from the copyright holder. To view a copy of this licence, visit http://creativecommons.org/licenses/by/4.0/.

\section{References}

Ainsworth, M. D. S. (1989). Attachments beyond infancy. American Psychologist, 44(4), 709-716. https:// doi.org/10.1037/0003-066X.44.4.709

Anderson, J. R., Van Ryzin, M. J., \& Doherty, W. J. (2010). Developmental trajectories of marital happiness in continuously married individuals: A group-based modeling approach. Journal of Family Psychology, 24(5), 587-596. https://doi.org/10.1037/a0020928

Antonucci, T. C., Akiyama, H., \& Takahashi, K. (2004). Attachment and close relationships across the life span. Attachment and Human Development, 6(4), 353-370. https://doi.org/10.1080/146167304200030 3136

Antonucci, T. C., Birditt, K. S., Sherman, C. W., \& Trinh, S. (2011). Stability and change in the intergenerational family: A convoy approach. Ageing and Society, 31(07), 1084-1106. https://doi.org/10.1017/ s0144686x1000098x

Antonucci, T. C., Lansford, J. E., \& Akiyama, H. (2001). Impact of positive and negative aspects of marital relationships and friendships on well-being of older adults. Applied Developmental Science, 5(2), 68-75. https://doi.org/10.1207/s1532480xads0502_2

Argyle, M. (2001). The psychology of happiness. Routledge.

Aron, A., Mashek, D., McLaughlin-Volpe, T., Wright, S., Lewandowski, G., \& Aron, E. N. (2005). Including close others in the cognitive structure of the self. In M. A. Baldwin (Ed.), Interpersonal cognition. The Guilford Press.

Aron, A., McLaughlin-Volpe, T., Mashek, D., Lewandowski, G., Wright, S. C., \& Aron, E. N. (2004). Including others in the self. European Review of Social Psychology, 15(1), 101-132. https://doi.org/10. 1080/10463280440000008

Baumeister, R. F. L., M. R. (1995). The need to belong: Desire for interpersonal attachments as a fundamental human motivation. Psychological Bulletin, 117(3), 497-529 https://doi.org/10.1037/0033-2909. 117.3.497

Beller, J., \& Wagner, A. (2018). Loneliness, social isolation, their synergistic interaction, and mortality. Health Psychology, 37(9), 808-813. https://doi.org/10.1037/hea0000605

Birditt, K. S., \& Antonucci, T. C. (2007). Relationship quality profiles and well-being among married adults. Journal of Family Psychology, 21(4), 595-604. https://doi.org/10.1037/0893-3200.21.4.595

Bodenmann, G., Hilpert, P., Nussbeck, F. W., \& Bradbury, T. N. (2014). Enhancement of couples' communication and dyadic coping by a self-directed approach: A randomized controlled trial. Journal of Consulting and Clinical Psychology, 82(4), 580-591. https://doi.org/10.1037/a0036356

Burger, E., \& Milardo, R. M. (1995). Exploratory study marital interdependence and social networks. Journal of Social and Personal Relationships, 12(3), 403-415. https://doi.org/10.1177/0265407595123005

Caunt, B., Franklin, J., Brodaty, N., \& Brodaty, H. (2013). Exploring the causes of subjective well-being: A content analysis of peoples' recipes for long-term happiness. Journal of Happiness Studies, 14(2), 475-499. https://doi.org/10.1007/s10902-012-9339-1

Cheng, S. T., Li, K. K., Leung, E. M. F., \& Chan, A. C. M. (2011). Social exchanges and subjective wellbeing: Do sources of positive and negative exchanges matter? The Journals of Gerontology Series b: Psychological Sciences and Social Sciences, 66B(6), 708-718. https://doi.org/10.1093/geronb/gbr061 
Cheung, E. O., Gardner, W. L., \& Anderson, J. F. (2015). Emotionships: Examining people's emotion-regulation relationships and their consequences for well-being. Social Psychological and Personality Science, 6(4), 407-414. https://doi.org/10.1177/1948550614564223

Chopik, W. J. (2017). Associations among relational values, support, health, and well-being across the adult lifespan. Personal Relationships, 24(2), 408-422. https://doi.org/10.1111/pere.12187

Corrigan, J. D., Kolakowsky-Hayner, S., Wright, J., Bellon, K., \& Carufel, P. (2013). The Satisfaction with Life Scale. The Journal of Head Trauma Rehabilitation, 28(6), 489-491. https://doi.org/10.1097/HTR. 0000000000000004

Coyne, J. C., \& DeLongis, A. (1986). Going beyond social support: The role of social relationships in adaptation. Journal of Consulting and Clinical Psychology, 54(4), 454-460.

Demir, M. (2015). Friendship and Happiness Across the Life-Span and Cultures. Springer.

Demir, M., Orthel-Clark, H., Özdemir, M., \& Bayram Özdemir, S. (2015). Friendship and Happiness Among Young Adults. In M. Demir (Ed.), Friendship and Happiness: Across the Life-Span and Cultures (pp. 117-135). Springer Netherlands. https://doi.org/10.1007/978-94-017-9603-3_7

Diener, E., Emmons, R. A., Larson, R. J., \& Griffin, S. (1985). The Satisfaction with Life Scale. Journal of Personality Assessment, 49(1), 71-75. https://doi.org/10.1207/s15327752jpa4901_13

Diener, E., \& Seligman, M. E. P. (2002). Very happy people. Psychological Review, 13(1), 81-84. https://doi.org/10.1111/1467-9280.00415

Dunbar, R. I. M. (2018). The Anatomy of Friendship. Trends in Cognitive Sciences, 22(1), 32-51. https://doi.org/10.1016/j.tics.2017.10.004

Dush, C. M. K., \& Amato, P. R. (2016). Consequences of relationship status and quality for subjective well-being. Journal of Social and Personal Relationships, 22(5), 607-627. https://doi.org/10.1177/ 0265407505056438

Dush, C. M. K., Taylor, M. G., \& Kroeger, R. A. (2008). Marital happiness and psychological well-being across the life course. Family Relations, 57(2), 211-226. https://doi.org/10.1111/j.1741-3729.2008. 00495.x

Fingerman, K. L., Hay, E. L., \& Birditt, K. S. (2004). The best of ties, the worst of ties: Close, problematic, and ambivalent social relationships. Journal of Marraige and Family, 66, 792-808. https://doi. org/10.1111/j.0022-2445.2004.00053.x

Fiori, K. L., Antonucci, T. C., \& Kortina, K. S. (2006). Social network typologies and mental health among older adults. Journals of Gerontology -- Series B Psychological Sciences and Social Sciences, 61(1), 25-32. https://doi.org/10.1093/geronb/61.1.P25

Fiori, K. L., Smith, J., \& Antonucci, T. A. (2007). Social network types among older adults: A multidimentional approach. Journal of Gerontology, 62B(6), 332-330. https://doi.org/10.1093/geronb/ 62.6.P322

Fraley, R. C., \& Shaver, P. R. (2000). Adult romantic attachment: Theoretical developments, emerging controveries, and unanswered questions. Review of General Psychology, 4(2), 132-154. https://doi. org/10.1037/1089-2680.4.2.132

Fredrickson, B. L., \& Joiner, T. (2002). Positive Emotions Trigger Upward Spirals Toward Emotional Well-Being. Psychological Science, 13(2), 172-175. https://doi.org/10.1111/1467-9280.00431

Fuller-Iglesias, H. R., Webster, N. J., \& Antonucci, T. C. (2013). Adult family relationships in the context of friendship. Research in Human Development, 10(2), 184-203. https://doi.org/10.1080/15427 609.2013.786562

Fuller-Iglesias, H. R., Webster, N. J., \& Antonucci, T. C. (2015). The complex nature of family support across the life span: Implications for psychological well-being. Developmental Psychology, 51(3), 277-288. https://doi.org/10.1037/a0038665

Gillespie, B. J., Lever, J., Frederick, D., \& Royce, T. (2014). Close adult friendships, gender, and the life cycle. Journal of Social and Personal Relationships, 32(6), 709-736. https://doi.org/10.1177/02654 07514546977

Hawkins, D. N., \& Booth, A. (2005). Unhappily ever after: Effects of long-term, low-quality marriages on well-being. Social Forces, 84(1), 451-471. https://doi.org/10.1353/sof.2005.0103

Henry, D. B., Tolan, P. H., \& Gorman-Smith, D. (2005). Cluster analysis in family psychology research. Journal of Family Psychology, 19(1), 121-132. https://doi.org/10.1037/0893-3200.19.1.121

Hoppmann, C. A., Gerstorf, D., Willis, S. L., \& Schaie, K. W. (2011). Spousal interrelations in happiness in the Seattle Longitudinal Study: Considerable similarities in levels and change over time. Developmental Psychology, 47(1), 1-8. https://doi.org/10.1037/a0020788

Wang, H., \& Wellman, B. (2010). Social connectivity in America: Changes in adult friendship network size from 2002 to 2007. American Behavioral Scientist, 53(8), 1148-1169. https://doi.org/10.1177/ 0002764209356247 
Huston, T. L., Caughlin, J. P., Houts, R. M., Smith, S. E., \& George, L. J. (2001). The connubial crucible: Newlywed years as predictors of marital delight, distress, and divorce. Journal of Personality and Social Psychology, 80(2), 237-252. https://doi.org/10.1037/0022-3514.80.2.237

International-Wellbeing-Group. (2013). Personal WellbeingIndex: 5th Edition. Centre on Quality of Life. Kassambara, A. (2017). Practical Guide to Cluster Analysis in R (1st ed.). STHDA.

Kaufman, V. A. (2020). Social Relationships and well-being: Rediscovering the importance of adult friendship [Doctoral Dissertation, University of California, Los Angeles]. Proquest. https://www. proquest.com/dissertations-theses/social-relationships-well-being-rediscovering/docview/24273 $02559 / \mathrm{se}-2$ ? accountid $=14512$

Ketchen, D. J., Jr., \& Shook, C. L. (1996). The application of cluster analysis in strategic management research: An analysis and critique. Stategic Management Journal, 17(6), 441-458. https://doi.org/ 10.1002/(SICI)1097-0266(199606)17:6\%3c441::AID-SMJ819\%3e3.0.CO;2-G

Lehmann, V., Tuinman, M. A., Braeken, J., Vingerhoets, A. J. J. M., Sanderman, R., \& Hagedoorn, M. (2014). Satisfaction with relationship status: Development of a new scale and the role in predicting well-being. Journal of Happiness Studies, 16(1), 169-184. https://doi.org/10.1007/s10902-014-9503-X

Lewis, D., M. G., Al-Shawaf, L., Russell, E. M., \& Buss, D. M. (2015). Friends and Happiness: An Evolutionary Perspective on Friendship. In M. Demir (Ed.), Friendship and happiness (pp. 37-57). Springer.

Litwin, H., \& Stoeckel, K. J. (2013). Confidant network types and well-being among older Europeans. The Gerontologist, 54(5), 762-772. https://doi.org/10.1093/geront/gnt056

Lyubomirsky, S., King, L., \& Diener, E. (2005). The benefits of frequent positive affect: Does happiness lead to success? Psychological Bulletin, 131(6), 803-855. https://doi.org/10.1037/0033-2909.131.6. 803

Mattingly, B. A., McIntyre, K. P., \& Lewandowski, G. W., Jr. (2012). Approach motivation and the expansion of self in close relationships. Personal Relationships, 19, 113-127. https://doi.org/10.1111/j.14756811.2010.01343.x

Milligan, G. W., \& Cooper, M. (1985). An examination of procedures for determining the number of clusters in a data set. Psychmetrika, 50(2), 159-179. https://doi.org/10.1007/BF02294245

Mirkin, B. (2013). Clustering -- A data recovery approach (2nd ed.). Taylor \& Francis Group.

Mohacsy, I. (1992). The Many Faces of Love. Contemporary Psychoanalysis, 28(1), 89-96. https://doi.org/ 10.1080/00107530.1992.10746739

Myers, D. G. (1999). Close relationships and Quality of Life. In E. D. D. Kahneman, \& N. Schwarz (Ed.), Well-Being: The foundation of hedonic psychology. Russell Sage Foundation.

North, R. J., Holahan, C. J., Moos, R. H., \& Cronkite, R. C. (2008). Family support, family income, and happiness: A 10-year perspective. Journal of Family Psychology, 22(3), 475-483. https://doi.org/10. 1037/0893-3200.22.3.475

Proulx, C. M., Helms, H. M., \& Buehler, C. (2007). Marital quality and personal qell-being: A meta-analysis. Journal of Marriage and Family, 69(3), 576-593. https://doi.org/10.1111/j.1741-3737.2007. 00393.x

Ratelle, C. F., Simard, K., \& Guay, F. (2012). University students' subjective well-being: The role of autonomy support from parents, friends, and the romantic partner. Journal of Happiness Studies, 14(3), 893-910. https://doi.org/10.1007/s10902-012-9360-4

Reis, H. T. (2001). Relationship experiences and emotional well-being. In C. D. Ryff \& B. H. Singer (Eds.), Emotion, social, relationships and health. Oxford University Press.

Sutcliffe, A., Dunbar, R., Binder, J., \& Arrow, H. (2012). Relationships and the social brain: Integrating psychological and evolutionary perspectives. British Journal of Psychology, 103(2), 149-168. https://doi. org/10.1111/j.2044-8295.2011.02061.x

Takahashi, K. (2005). Toward a life span theory of close relationships: The affective relationships model (Vol. 48). Karger.

Thomas, P. A. (2016). The impact of relationship-specific support and strain on depressive symptoms across the life course. Journal of Aging and Health, 28(2), 363-382. https://doi.org/10.1177/0898264315 591004

VanderDrift, L. E., Wilson, J. E., \& Agnew, C. R. (2012). On the benefits of valuing being friends for nonmarital romantic partners. Journal of Social and Personal Relationships, 30(1), 115 - 131. https://doi. org/10.1177/0265407512453009

Walen, H. R., \& Lachman, M. E. (2000). Social support and strain from partner, family, and friends: Costs and benefits for men and women in adulthood. Journal of Social and Personal Relationships, 17(1), 5-30. https://doi.org/10.1177/0265407500171001

Wright, P. H. (1969). A model and a technique for studies of friendships. Journal of Experimental Social Psychology, 5(3), 295-309. https://doi.org/10.1016/0022-1031(69)90055-9 
Yim, O., \& Ramdeen, K. T. (2015). Hierarchical cluster analysis: Comparison of three linkage measures and application to psychological data. The Quantitative Methods for Psychology, 11(1), 8-21. https://doi. org/10.20982/tqmp.11.1.p008

Zeifman, D. M., \& Hazan, C. (2018). Pair bonds as attachments-Mounting evidence in support of Bowlby's Hypothesis. The Guilford Press.

Publisher's Note Springer Nature remains neutral with regard to jurisdictional claims in published maps and institutional affiliations. 